\title{
TR-644 a novel potent tubulin binding agent induces impairment of endothelial cells function and inhibits angiogenesis
}

\author{
Elena Porcù - Giampietro Viola $\cdot$ Roberta Bortolozzi - Luca Persano • \\ Stefania Mitola • Roberto Ronca - Marco Presta - Romeo Romagnoli • \\ Pier Giovanni Baraldi • Giuseppe Basso
}

Received: 20 November 2012/ Accepted: 22 February 2013/Published online: 2 March 2013

(C) Springer Science+Business Media Dordrecht 2013

\begin{abstract}
TR-644 is a novel combretastatin A-4 (CA-4) analogue endowed with potent microtubule depolymerizing activity superior to that of the lead compound and it also has high affinity to colchicines binding site of tubulin. We tested TR-644 anti-angiogenic effects in human umbilical endothelial cells (HUVEC). It showed no significant effects on the growth of HUVEC cells at concentrations below $1,000 \mathrm{nM}$, but at much lower concentrations (10-100 nM) it induced inhibition of capillary tube formation, inhibition of endothelial cell migration and affected endothelial cell morphology as demonstrated by the disruption of the microtubule network. TR-644 also increased permeability of HUVEC cells in a time dependent manner. The molecular mechanism for the anti-vascular activity of TR644 was investigated in detail. TR-644 caused G2/M arrest in endothelial cells and this effect correlated with downregulation of the expression of $\mathrm{Cdc} 25 \mathrm{C}$ and $\mathrm{Cdc} 2^{\text {Tyr15. }}$.
\end{abstract}

Elena Porcù and Giampietro Viola: equal contribution.

E. Porcù · G. Viola $(\bowtie) \cdot$ R. Bortolozzi · L. Persano · G. Basso Laboratorio di Oncoematologia, Dipartimento di Salute della Donna e del Bambino, Università di Padova, Via Giustiniani 3, 35128 Padua, Italy

e-mail: giampietro.viola.1@unipd.it

S. Mitola $\cdot$ R. Ronca $\cdot$ M. Presta

Unit of General Pathology and Immunology, Department of Biomedical Sciences and Biotechnology, University of Brescia, Brescia, Italy

R. Romagnoli · P. G. Baraldi

Dipartimento di Scienze Farmaceutiche, Università di Ferrara, 44100 Ferrara, Italy
Moreover TR-644 inhibited VEGF-induced phosphorylation of VE-cadherin but did not prevent the VEGF-induced phosphorylation of FAK. In chick chorioallantoic membrane in vivo assay, TR-644 (0.1-1.0 pmol/egg) efficiently counteracted the strong angiogenic response induced by FGF. Also CA-4, used as reference compound, caused an antagonistic effect, but in contrast, it induced per se, a remarkable angiogenic response probably due to an inflammatory reaction in the site of treatment. In a mice allogenic tumor model, immunohistochemical staining of tumors with anti-CD31 antibody showed that TR-644 significantly reduced the number of vessel, after $24 \mathrm{~h}$ from the administration of a single dose $(30 \mathrm{mg} / \mathrm{Kg})$.

Keywords Angiogenesis - HUVEC - Vascular disrupting agents $\cdot$ Combretastatin $\cdot$ VE-cadherin

\section{Introduction}

The microtubule system of eukaryotic cells is a critical element in a variety of fundamental cellular processes, such as cell division, formation and maintenance of cell shape, regulation of motility, cell signalling, secretion and intracellular transport [1]. Among the various strategies developed to block mitosis, microtubules represent an attractive target for numerous small natural and synthetic molecules that inhibit the formation of the mitotic spindle $[1,2]$. Besides the ability to inhibit tumor cell proliferation, microtubule-targeting drugs have also been shown to have activity against the vasculature in tumors [3, 4]. Since the tumor vasculature differs from that of normal tissues, in recent years, the abnormal structure and function of tumor blood vessels have been studied in the attempt to attack and destroy solid tumors. These vascular abnormalities consist 
of temporary occlusions, a rapidly dividing endothelial population, blind ends, leaky vessels, and a reduction in blood vessel coverage by pericytes. In addition, the structure of the tumor blood vessel wall is also abnormal, which is evident by uneven vessel diameter and defects in their endothelial lining, as well as the presence of endothelial cells undergoing apoptosis. In contrast, normal vasculature is organized with vessels close enough to each other to ensure adequate nutrient and oxygen supply to all cells. Tumor-vascular disrupting agents (VDAs) are a new class of anti-cancer drugs that show strong promise in treating a variety of solid tumors [4]. In contrast to antiangiogenic therapy, which inhibits the outgrowth of new blood vessels, VDAs treatments selectively attack the existing tumor vasculature. Several low-molecular-weight VDAs are currently in clinical trials or undergoing preclinical testing. One of the most important antimitotic agents and vascular disrupting agents is combretastatin A-4 (CA-4, Fig. 1). CA-4, isolated from the bark of the South African tree Combretum caffrum is one of the well-known natural molecules that strongly inhibits tubulin polymerization by binding to the colchicine binding site. CA-4 shows potent cytotoxicity against a wide variety of human cancer cell lines, including those displaying multidrug resistant. A water-soluble disodium phosphate derivative of CA-4 (named CA4-P) has shown promising results in human cancer clinical trials. The proposed mechanism of CA4-P for rapid tumor vascular shutdown assumes that the compound induces changes in endothelial-cell shape, plasma membrane blebbing, and increases the permeability of cell monolayers. These changes in endothelial cells result in increases in vascular resistance to blood flow and increases vascular permeability and in vasoconstriction, subsequently leading to vascular shutdown. CA4 has tumor vascular damaging effects at well-tolerated doses of CA4-P in animal models [5]. Recently, CA4-P has received orphan drug designation for the treatment of anaplastic thyroid cancer, medullary thyroid cancer, and stage IV papillary or follicular thyroid cancer. Despite its efficacy CA4-P presents some side-effects in particular tumor pain.

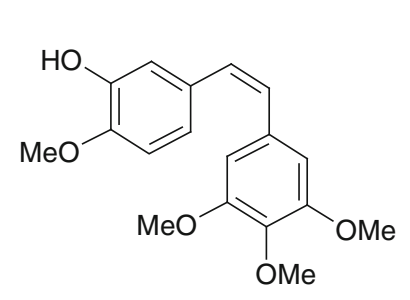

CA4

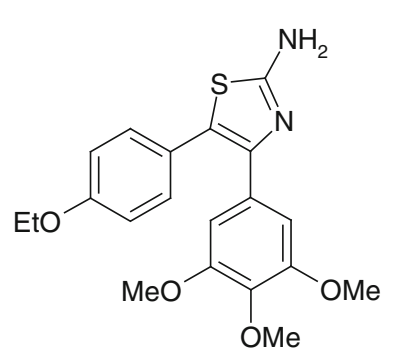

TR644
Fig. 1 Chemical structures of compounds
Therefore, many synthetic analogues were synthesized making structural modification of the CA4 in order to develop new compounds with more activity and fewer adverse reactions. Previous structure-activity relationship studies demonstrated that both the $3^{\prime}, 4^{\prime}, 5^{\prime}$-trimethoxy substitution pattern on the A-ring and the cis-olefin configuration at the bridge were fundamental requirements for optimal activity, while B-ring structural modifications were tolerated by the target [6]. However, the cis-configuration of CA-4 is prone to isomerize to the thermodynamically more stable trans-form during storage and metabolism, resulting in a dramatic decrease in its activity [7]. Thus, to retain the appropriate geometry of the two adjacent aryl groups required for a potent bioactivity, chemically stable cis-restricted derivatives of CA-4 were obtained by incorporating the olefinic double bond with vicinal diarylsubstituted five-member aromatic heterocyclic rings, such as pyrazole [8], imidazole [9], thiazole [10], furazan (1,2,5oxadiazole) [11], isoxazole [12], oxazole [8], 1,2,3-thiadiazole [13], triazole [14] and 1,2,3,4-tetrazole [10]. We recently synthesized [15] a new series of 2-amino-4- $\left(3^{\prime}, 4^{\prime}, 5^{\prime}\right.$-trimethoxyphenyl)-5-aryl thiazoles in which we identified compound TR-644 as the most active compound (Fig. 1). It has been shown that this compound is endowed with high antiproliferative effects with $\mathrm{IC}_{50}$ values in the nanomolar range in different cancer cell lines. Here we show that this compound is endowed with pronounced in vitro antivascular effects at subtoxic concentrations and appears to disrupt the vasculature in vivo both in tumor tissue and in the chick chorioallantoic membrane, without any evident toxic effect.

\section{Materials and methods}

\section{Drugs and cell culture}

TR-644 was synthesized as previously described [15]. Combretastatin A4 (CA4) and CA4-P were synthesized as described [16-18]. HUVECs were prepared from human humbelical cord veins, as previously described [19]. The adherent cells were maintained in M200 medium additioned by LSGS (Low Serum Growth Supplement), containing FBS, Hydrocortisone, hEGF, bFGF, heparin, gentamycin/ amphotericin (Life technologies, Monza, Italy). Once confluent, the cells were detached by trypsin-EDTA solution and used in experiments from the first to sixth passages. BL6-B16 murine melanoma cells were maintained in DMEM supplemented with $10 \%$ fetal calf serum (FCS).

Cytotoxicity and apoptosis assays

Cytotoxicity assay were carried out with trypan blue test as described previously [20]. Surface exposure of phosphatidylserine on apoptotic cells was measured by flow cytometry 
with a Coulter Cytomics FC500 (Beckman Coulter) using Annexin-V-Fluos kit to cells according to the manufacturer's instructions (Annexin-V Fluos, Roche Diagnostic, Monza, Italy). Simultaneously the cells were stained with PI.

\section{Colony forming assay}

HUVECs were plated at $1 \times 10^{3}$ cells/well in six-well plates to provide an optimal counting density. Cells were treated with compounds at different concentration. After $24 \mathrm{~h}$, medium was replaced with fresh one and cells were cultured for 1-2 weeks until well-defined colonies had formed (replacing culture medium every 2-3 days). Cells were briefly washed with $0.9 \%$ saline solution and stained with $0.5 \%$ crystal violet in $20 \%$ methanol. Colonies of $\geq 50$ cells were then counted visually.

\section{Motility assay}

Motility assay for HUVECs was based on "scratch" wounding of a confluent monolayer [21]. Briefly, HUVECs $\left(1 \times 10^{5}\right)$ were seeded onto $0.1 \%$ collagen type I (BD Biosciences, Italy)-coated six well plates in complete medium until a confluent monolayer was formed. The cells were scratch wounded using a pipette tip and wells were washed with PBS to remove the undetached cells. Then, the cells were treated with the test compounds and at different times from the scratch, the cells were photographed under a light microscope $(10 \times$ magnification). At all indicated time points, the wound width was measured in four areas and compared with the initial width.

\section{Endothelial cell vessel formation on Matrigel matrix}

Matrigel matrix (Basement membrane matrix, BD Biosciences, Italy) was kept at $4{ }^{\circ} \mathrm{C}$ for $3 \mathrm{~h}$. $230 \mu \mathrm{l}$ of Matrigel were added to each well of a 24-well plate. After gelling at $37{ }^{\circ} \mathrm{C}$ for $30 \mathrm{~min}$, gels were overlaid with $500 \mu \mathrm{l}$ of medium containing $6 \times 10^{4}$ HUVEC cells, incubated over Matrigel for $6 \mathrm{~h}$ to allow the capillary tubes to form. Different concentrations of TR-644 were added in the cultures and incubated for different times and the disappearance of existing vasculature was monitored and photographed (five fields for each well: the four quadrants and the center) at a $10 \times$ magnification. Phase contrast images were recorded using a digital camera and save as TIFF files. Image analysis was carried out using the ImageJ image analysis software and the following dimensional parameters (percent area covered by HUVECs and total length of HUVECs network per field), and topological parameters (number of meshes and branching points per fields) were estimated [22]. Values were expressed as percent change from control cultures grown with complete medium.
Endothelial cell permeability assay

HUVEC cells were seeded at a density of $3 \times 10^{5}$ cells per well into 24 -well cell culture inserts $(1.0 \mu \mathrm{m}$, Falcon, Mantova, Italy) and incubated for $24 \mathrm{~h}$ to allow a confluent cell monolayer to form. Drugs at varying concentrations were added to the cells at the upper chamber and incubated for different times at $37{ }^{\circ} \mathrm{C}$. At the same time, FITC-dextran (Fluorescein Isothiocyanate-dextran $40 \mathrm{kDa}$, SigmaAldrich, Milano, Italy) — was added to the upper chamber. The effects of TR-644 and CA4 on HUVEC monolayer permeability were monitored using a fluorescent plate reader (Victor ${ }^{3}$ Perkin Elmer) as measured by increased fluorescent signal in the lower chamber as a function of time.

Cell adhesion assay

HUVECs were seeded in six-well plates to provide an optimal density and treated with compounds at different concentrations. After $24 \mathrm{~h}$, cells were trypsinized and plated in quadruplicate on a 96-well plate at $5 \times 10^{4}$ cells per well. Cells were allowed to attach for $20 \mathrm{~min}$ at $37^{\circ} \mathrm{C}$, and then unattached cells were gently removed. Adherent cells were washed three times with PBS and incubated with 3-(4,5-dimethylthiazol-2-yl)-2,5-diphenyl tetrazolium bromide. MTT test was performed as previously described [23] to quantify the attached cells.

\section{Immunofluorescence analysis}

Cells were fixed in cold $4 \%$ formaldehyde for $15 \mathrm{~min}$, rinsed and stored prior to analysis. Primary antibody staining was performed for $\beta$-tubulin (mouse, monoclonal 1:1,000, Sigma-Aldrich, Milano, Italy). After incubation, cells were washed and incubated with a secondary antibody Alexa conjugated (1:2,000, Life technologies, Monza, Italy). Cells were counterstained with DAPI (1:10,000, Sigma-Aldrich, Milano, Italy). For F-actin visualization the cells were fixed as above and stained with phalloidin-tetramethylrhodamine B isothiocyanate conjugate (Sigma-Aldrich, Milano, Italy). Images were obtained on a video-confocal microscope (Vico, Ecliple Ti80, Nikon), equipped with a digital camera.

\section{Western blot analysis}

HUVECs cells were incubated in the presence of test compounds and, after different times, were collected, centrifuged and washed two times with ice cold phosphate-buffered saline (PBS). The pellet was then resuspended in lysis buffer. After $30 \mathrm{~min}$ of incubation in ice, cells were lysed on ice for $30 \mathrm{~min}$, lysates were centrifuged at $15,000 \times g$ at $4{ }^{\circ} \mathrm{C}$ for $10 \mathrm{~min}$ and the supernatant collected. The protein 
concentration in the supernatant was determined using the BCA protein assay reagents (Pierce, Milano, Italy). Equal amounts of protein $(10 \mu \mathrm{g})$ were resolved using sodium dodecyl sulfate polyacrylamide gel electrophoresis (SDSPAGE) (7.5-15\% acrylamide gels) and transferred to PVDF Hybond-p membrane (GE Healthcare, Milano, Italy). Membranes were blocked with ECL Advance Blocking Agent (GE Healthcare, Milano, Italy) for $2 \mathrm{~h}$ at room temperature. Membranes were then incubated overnight at $4{ }^{\circ} \mathrm{C}$ with primary antibodies against, $\mathrm{p}-\mathrm{cdc} 2^{\mathrm{Tyr} 15}, \mathrm{cdc} 25 \mathrm{c}$ (Cell Signaling, Milano, Italy), cyclin B (BD Biosciences, Italy), FAK $^{\mathrm{Tyr} 397}$ (BD Biosciences, Italy) and VE-cadherin ${ }^{\text {Tyr658 }}$ (Abcam). Membranes were next incubated with peroxidaselabeled secondary antibodies for $60 \mathrm{~min}$. All membranes were visualized using ECL Advance (GE Healthcare, Milano, Italy) and exposed to Hyperfilm MP (GE Healthcare, Milano, Italy). To ensure equal protein loading, each membrane was stripped and reprobed with anti- $\beta$-actin antibody(Sigma-Aldrich, Milano, Italy).

\section{CAM assay in fertilized chicken eggs}

Alginate pellets containing 0.1-1.0 pmol per pellet of TR644 or CA4 were grafted on the chorioallantoic membrane (CAM) of fertilized chicken eggs at day 11 [24]. After $72 \mathrm{~h}$ new blood vessels converging toward the implant were counted at $5 \times$ magnification under a stereomicroscope.

\section{Tumorigenesis studies}

Procedures involving animals and their care conformed with institutional guidelines that comply with national and international laws and policies (EEC Council Directive 86/609, OJ L 358, 12 December 1987). Six week old C57BL/6 mice (Charles River, Calco, Italy) were injected s.c. into the dorsolateral flank with $10^{5}$ BL6-B16 murine melanoma cells in $200 \mu \mathrm{l}$-total volume of PBS. When tumor volume reached $300 \mathrm{~mm}^{3}$ of volume, animals were treated i.p with $50 \mu \mathrm{l}$ of CA-4P $(30 \mathrm{mg} / \mathrm{kg})$, TR-644 (30 mg/kg) dissolved in DMSO. Twenty-four hours later tumors where harvested, embedded in OCT-compound (Bio-Optica) and immediately frozen in liquid nitrogen for immunohistochemical analysis.

Immunohistochemistry and immunofluorescence of tumor tissues

Excised tumors were cut with a cryostat in $4-5 \mu \mathrm{m}$ sections. Immunohistochemistry was performed by staining samples with rat anti-mouse CD31 antibody (1:200; BD Biosciences) and biotinylated goat anti-rat secondary antibody (1:100; BD Biosciences). The detection of tumor vasculature was performed using HRP-conjugated streptavidin (1:500; Jackson ImmunoResearch Laboratories). The microvessel density (MVD) was evaluated by counting the number of vessels in 5 fields per section, using a $40 \times$ objective. For subsequent experiments, samples were formalin-fixed and paraffin embedded and then stained with mouse primary antibody against proliferating cell nuclear antigen PCNA (1:100; Santa Cruz) and AlexaFluor secondary antibody (1:2,000, Life technologies, Monza, Italy). Proliferating cells were determined by counting the number of PCNA-positive cells on DAPIpositive cells (values expressed as percent of PCNA + cells/DAPI + cells), in 3 fields for each section, with a $40 \times$ objective. A staining with hematoxylin and eosin (HE) was also performed to visualize the histological features of tumors. All specimens were viewed under a video-confocal microscope (Vico, Ecliple Ti80, Nikon), equipped with a digital camera, and images were captured using a $10 \times$ objective.

Statistical analyses

Unless indicated differently, the results are presented as mean \pm SEM. The differences between different treatments were analysed, using the two-sided Student's $t$ test. $P$ values lower than 0.05 were considered significant.

\section{Results}

TR-644 inhibits HUVEC migration and tube formation

To investigate the effects of TR-644 on endothelial cell migration, we scraped confluent monolayers of HUVEC to clear space for motile cells to move into. As shown in Fig. 2 (panels A and B) we observed that TR-644 inhibited HUVEC migration in a concentration and time-dependent manner. For comparison, we studied the effects of CA-4 in the same experimental conditions. CA- 4 treatment displayed similar effects, with a more pronounced inhibition of cell migration at the concentration of $5 \mathrm{nM}$ (Fig. 2, panel C) at which TR-644 is barely effective.

We also tested the effects of TR-644 on tubules formation assay, a well known in vitro angiogenesis test. After $18 \mathrm{~h}$ from cells seeding on Matrigel, HUVEC form a rich meshwork of branching capillary-like tubules with multicentric junctions. In the presence of TR-644, at different concentration and after $3 \mathrm{~h}$ of incubation, we observed that the capillary-like tubes were interrupted (1-10 nM) and at higher concentration $(100 \mathrm{nM})$ most cells were spherical either isolated or aggregated in small clumps (Fig. 3, panel A). These effects started to occur after $1 \mathrm{~h}$ of incubation and further increased after $6 \mathrm{~h}$ of incubation (Data not shown). 
A
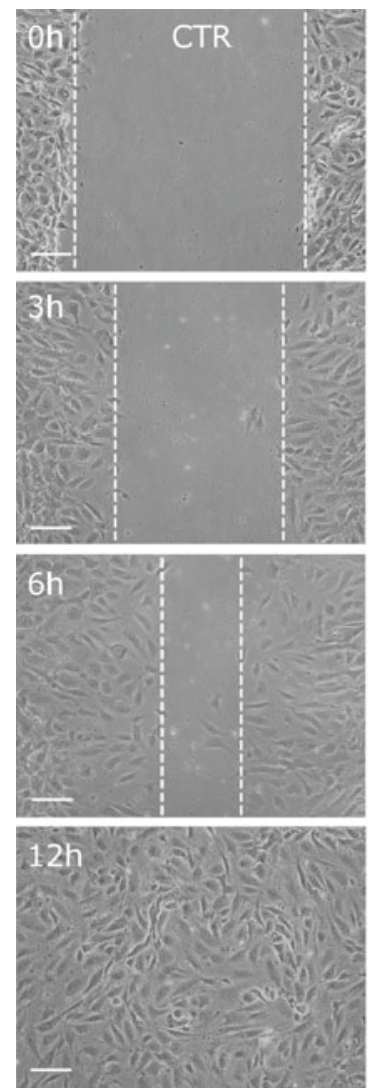
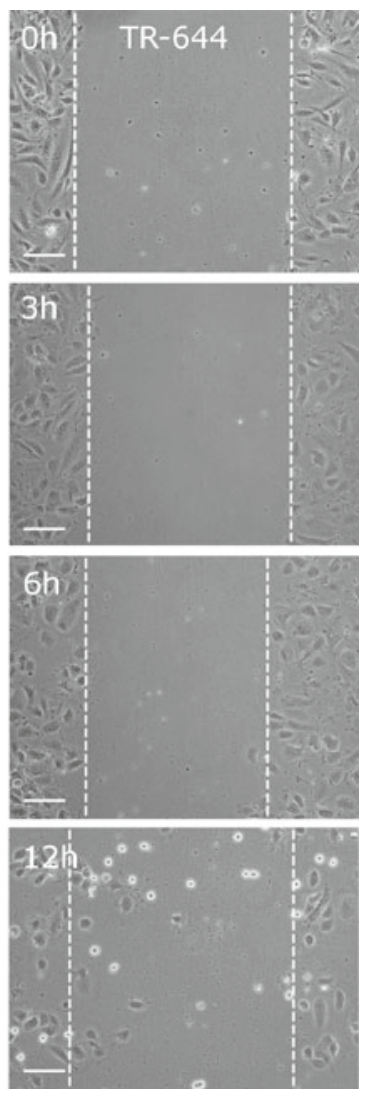

Fig. 2 TR-644 inhibits HUVEC migration. a Confluent HUVEC monolayer were scratch wounded and the cells were treated with different concentration of TR-644 or CA-4 and at different times cells were photographed, $\times 40$ magnification; Bar $=10 \mu \mathrm{m}$. The dotted lines define the areas lacking cells. Graphs show the quantitative

Quantitative image analysis showed that TR-644 (10-100 nM), significantly decreased both dimensional (percent of area covered by HUVECs, total length per field) and topological parameters (number of meshes per field, and number of branching points) of the capillary-like network (Fig. 3, panel B). Similar results were obtained with CA-4 (Fig. 3, panel B).

Moreover we evaluated the inhibitory effects of TR644 on tube formation. In this case, drugs were added simultaneously at the time of seeding. After $3 \mathrm{~h}$ of incubation we found a strong inhibition of capillary formation in comparison to untreated cells, in which we observed the polygonal structures (mesh) already formed (Fig. 3, panel C). It is interesting to note that in this case the effect of TR-644 was evident and significant also at the lowest concentration used $(1 \mathrm{nM})$ and was higher than that of CA4 (Fig. 3, panel D), suggesting that TR-644 strongly intefered with the ability of HUVEC to form capillary-like structures in vitro.

B
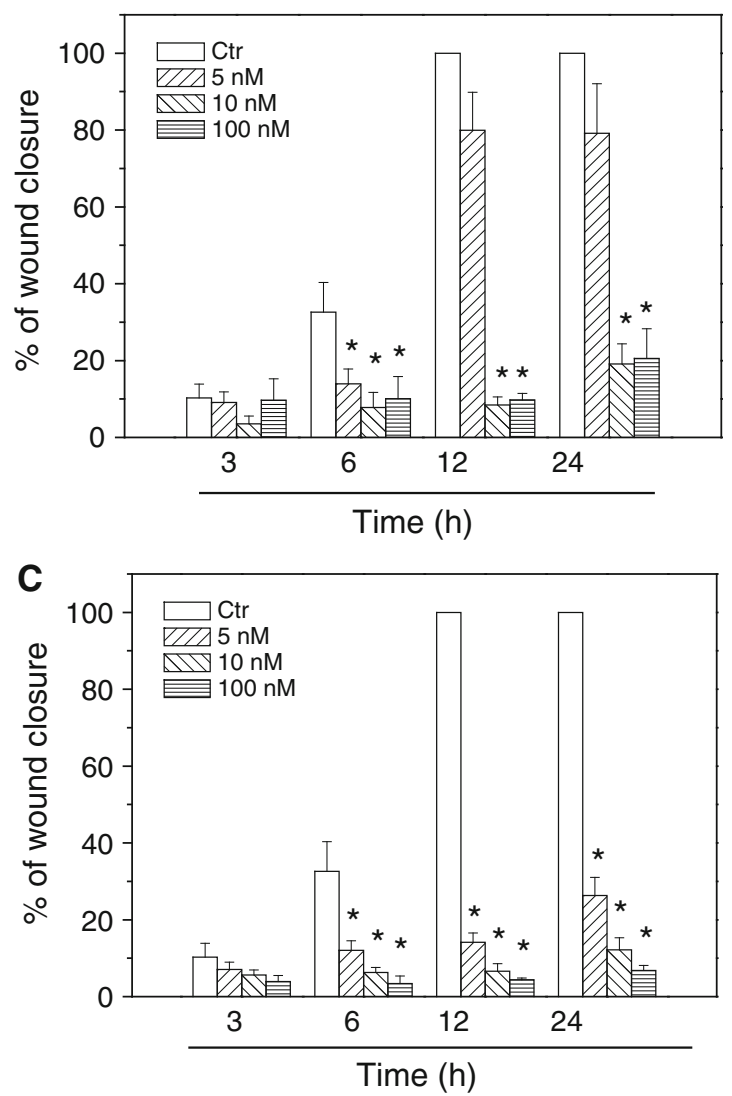

effect of TR-644 (b) and CA-4 (c) chosen as reference compound. Migration was quantified by measuring the gap closure at the indicated times as showed in a. Data were represented as mean \pm SEM of three independent experiments. $* P<0.01$ versus control

TR-644 increases permeability of the vascular endothelial monolayer

Changes in endothelial cell monolayer permeability also provide an in vitro model of tumor vascular disruption. The increase in permeability induced by the tested compounds, was evaluated in 24-well cell culture, where a confluent HUVEC monolayer was formed and monitoring the fluorescent signal of FITC-dextran in the lower chamber as a function of time. As shown in Fig. 4, a significant increase in endothelial cell permeability was observed when the confluent monolayers were treated with 10 and $100 \mathrm{nM}$ TR-644 (panel A) whereas CA-4 (panel B) displayed a similar profile.

TR-644 is not cytotoxic at the concentrations that induce vascular effects

To evaluate if the inhibition of cell migration and tube formation are due to a cytotoxic action of the drug we 

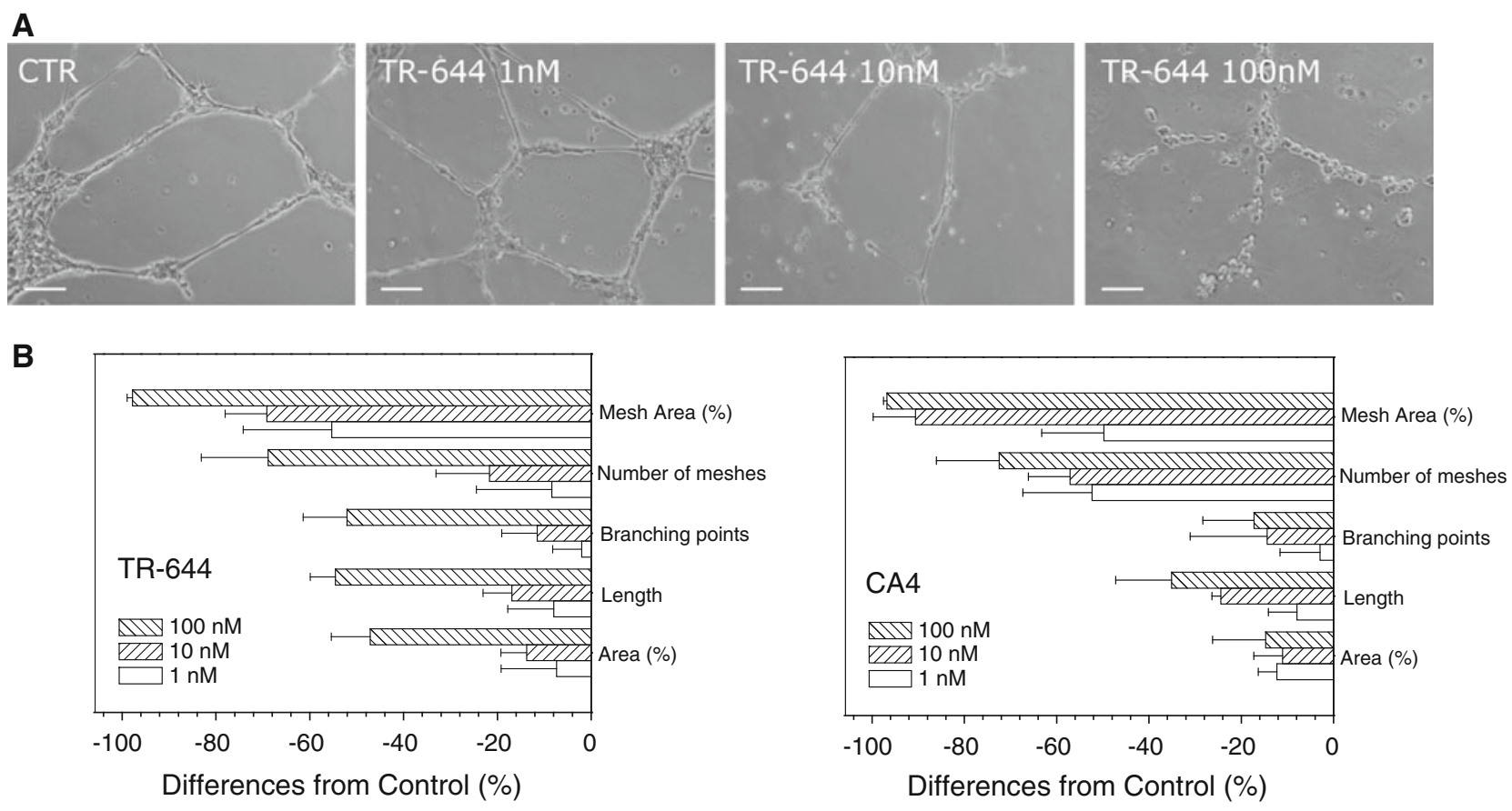

C
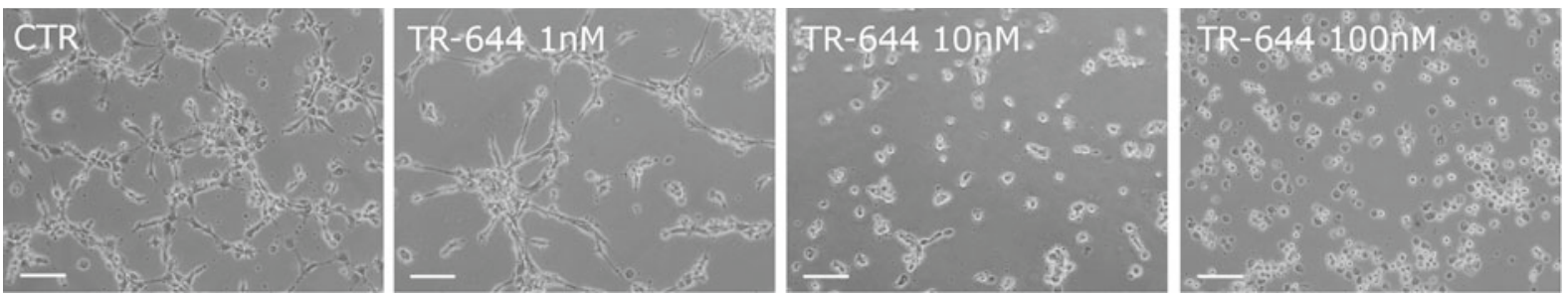

D

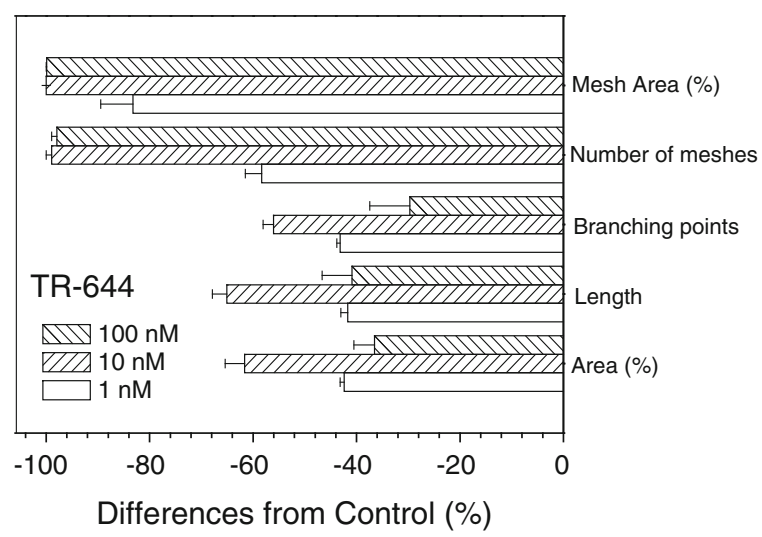

Fig. 3 Inhibition of endothelial cell capillary-like tubules formation by TR-644. Tubules formation on Matrigel was carried out as described in "Materials and methods". a Representative pictures $(\times 10$ magnification; Bar $=10 \mu \mathrm{m})$ of preformed capillary-like tubules treated with increasing concentration of TR-644 for $3 \mathrm{~h}$. b quantitative analysis of the effects of TR-644 and CA4 on the dimensional and topological parameters of the preformed capillary-

analyzed cell proliferation at different times of incubation by trypan blue count.

As shown in Fig. 5 (panel A), with TR-644 we observed a modest reduction of the number of cells occurring only at

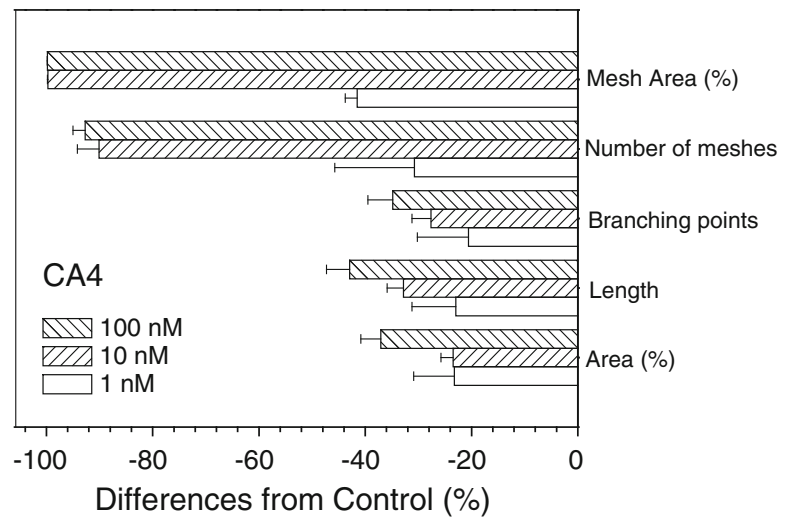

like tubules network. Data were represented as mean \pm SEM of three independent experiments. $\mathbf{c}$ Representative pictures $(\times 10$ magnification; $B a r=10 \mu \mathrm{m})$ of HUVEC in Matrigel treated with increasing concentration of TR-644 for $3 \mathrm{~h}$. d quantitative analysis of the effects of TR-644 and CA4 on the dimensional and topological parameters of the capillary-like tubules network. Data were represented as mean \pm SEM of three independent experiments

longer times of incubation (48-72 h). At lower concentration $(10 \mathrm{nM})$, after $24 \mathrm{~h}$ of incubation, no reduction of the viability was found while at 48 and $72 \mathrm{~h}$ of incubation the viability decreased to 38 and $43 \%$ respectively. For 

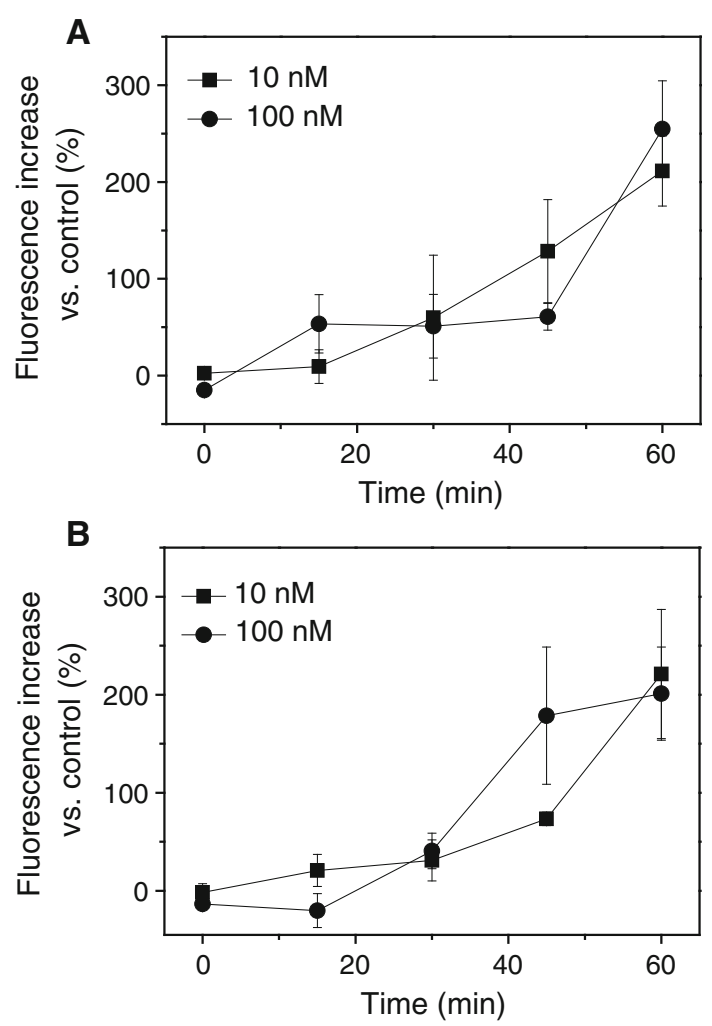

Fig. 4 TR-644 increased the permeability of an endothelial cell layer. HUVEC cells were seeded onto $0.1 \%$ collagen-coated 24-well insert wells in complete medium until a confluent monolayer was formed. They were then treated with the indicated concentrations of TR-644 (a) or CA4 (b). Simultaneously FITC-dextran was also added and its passage into the lower chamber was monitored at the indicated times. Data were represented as mean \pm SEM of three independent experiments

comparison CA-4 was also evaluated (Fig. 5, panel B) and we observed a marked reduction of cell number also at the concentration of $10 \mathrm{nM}$ for which we note a reduction of about $45 \%$ after $24 \mathrm{~h}$ incubation relative to untreated cells. We also carried out a clonogenic assay in which we observed that TR-644 had no effect at concentration lower than $10 \mathrm{nM}$ in comparison to CA4 which was more toxic than TR-644 of an order of magnitude (Fig. 5, panel C).

To further confirm that TR-644 is not cytotoxic for endothelial cells we performed flow cytometric AnnexinV/PI assay of HUVEC cells. As showed in Fig. 5 (panel D), we observed only a slight reduction of the cell viability at time points in which, as described above, we observed antivascular effects of the drug. Even at longer times of incubation $(24 \mathrm{~h})$ and highest concentration $(100 \mathrm{nM})$ no signes of apoptosis were detected.

TR-644 induces G2/M arrest of the cell cycle in HUVEC cells

The effect of TR-644 on cell cycle progression was examined by flow cytometry. TR-644 treatment resulted in the accumulation of cells in the G2/M phase, with a concomitant reduction in the proportion of cells in the G1 phase after $24 \mathrm{~h}$ of treatment. These changes started to occur at the concentration of $10 \mathrm{nM}$ (Fig. 6, panel A). A small decrease, although not significant, of cells in the $\mathrm{S}$ phase was also observed.

Next, we investigated the association between TR644induced G2/M arrest and alterations in G2/M regulatory protein expression. Cell arrest at the prometaphase/metaphase to anaphase transition is normally regulated by the mitotic checkpoint. In eukaryotic cells the activation of $\mathrm{Cdc} 2$ kinase is necessary for occurrence of the G2/M transition of the cell cycle. Activation of the kinase requires its dephosphorylation at Tyr15 and Thr14 by the phosphatase Cdc25 and accumulation of the cyclin B protein. As shown in Fig. 6 (panel B), TR-644 caused a decrease in cyclin B1 expression at $10 \mathrm{nM}$ while at $100 \mathrm{nM}$ we observed a significant increase. $\mathrm{Cdc} 2^{\text {Tyr15 }}$ and Cdc25 levels decreased both at 10 and $100 \mathrm{nM}$. Altogether these results indicate that arrest at G2/M induced by TR-644 is accompanied by a decreased expression of cyclin $\mathrm{B} 1$ at lower concentration whereas at higher concentration by an increase and by a remarkable decrease of $\mathrm{Cdc} 25 \mathrm{c}$ and $\mathrm{p}-\mathrm{Cdc} 2^{\mathrm{Tyr} 15}$.

Effects of TR-644 on microtubules and actin microfilament in HUVEC cells

We investigated the effects of TR-644 on the cytoskeleton proteins microtubules and actin micrfilaments. As shown in Fig. 7, the microtubule network exhibited normal arrangement and organization in HUVEC cells in the absence of drug treatment as well as when the cells were incubated with the lower concentration of drug $(1 \mathrm{nM})$. In contrast, $24 \mathrm{~h}$ of exposure to $10 \mathrm{nM}$ TR-644 caused microtubule disassembly, with induction, in about $20 \%$ of the cells, of spherical morphology. Exposure to the compound at $100 \mathrm{nM}$ resulted in an almost complete loss of microtubules. Similar results were obtained for CA-4 although the observed changes were more marked.

In agreement to the changes in cellular microtubules, cells treated with TR-644 showed minimal effects in the arrangement and amount of F-actin (Fig. 8), at low concentration $(1 \mathrm{nM})$ respect to the untreated cells. On the contrary the actin cytoskeleton started to disorganize both with TR-644 and CA4 (10 nM), resulting in the disappearance of actin fibers and in their relocalization and reorganization in intracellular focal adhesion regions, whereas the cytoskeleton was completely altered at higher concentration of both TR-644 and CA-4.

TR-644 reduces VE-cadherin phosphorylation

VE-cadherin is a member of cadherin superfamily, expressed by vascular endothelial cells [25]. In these cells, it is the major 

HUVEC cells viability. HUVEC collagen-coated 24-wells and then treated with the indicated concentrations of TR-644 (a) or CA4 (b). At different times $(0,24,48$ and $72 \mathrm{~h})$ cells were trypsinized and viability was determined by trypan blue exclusion assay. Data were represented as mean \pm SEM of three independent experiments. c. Representative dishes and quantitative data on the inhibitory effects of TR-644 and CA4 on HUVEC proliferation evaluated by clonogenic assay. Data were represented as mean \pm SEM of three independent experiments. d. HUVEC plated as described above were assayed for apoptosis by flow cytometry using an Annexin-V/PI assay kit
Fig. 5 Effects of TR-644 on were plated on onto $0.1 \%$
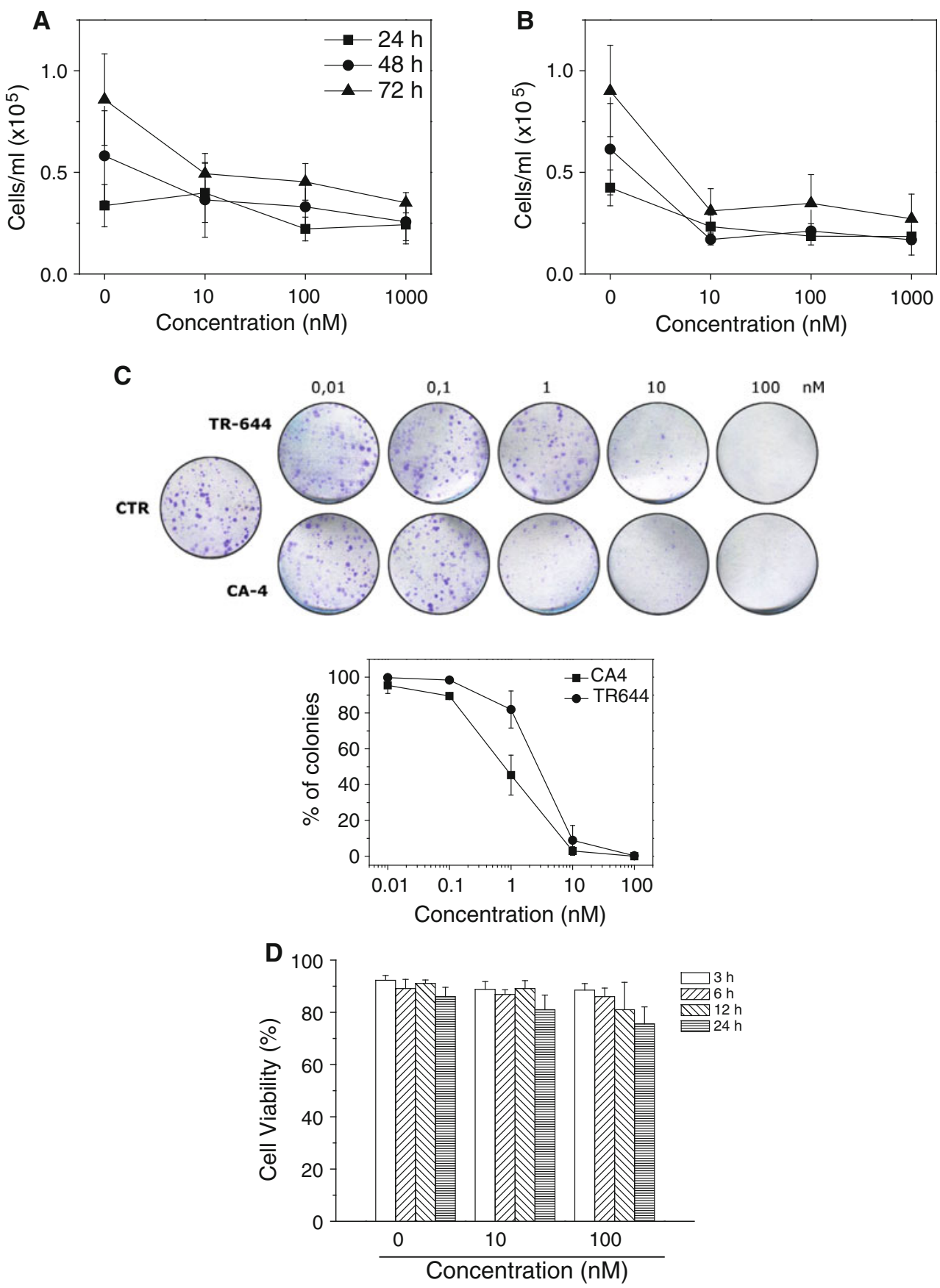

adherence junction protein, which, by modulating cell-cell adhesion, regulates angiogenesis, and vascular permeability. It is also required for differentiation into vasculature-like structures by endothelial cells in vitro [26, 27]. Since VEcadherin is crucial for controlling the state of adherence junctions, which in turn regulate endothelial cell-cell adhesion, cell motility, morphogenesis and intracellular signaling pathways, this molecule has many clinical implications. As showed above, TR-644 increased HUVEC permeability and VE-cadherin was mainly non-phosphorylated in quiescent vessels, thus we evaluated if this compound was able to reduce VE-cadherin phosphorylation following VEGF stimuli. VEGF rapidly induced the phosphorylation of VE-cadherin, triggering modifications of the adherence junction that is thought to allow for the loosening of cell-cell contacts that would be required for the sprouting of a new vessel [28]. As shown in Fig. 9 (panel A), TR-644 remarkably reduced the VEGF-induced VE-cadherin phosphorylation at Tyr658, both at 10 and $100 \mathrm{nM}$. In comparison also CA4 reduced the phosphorylation as previously demonstrated [29]. 

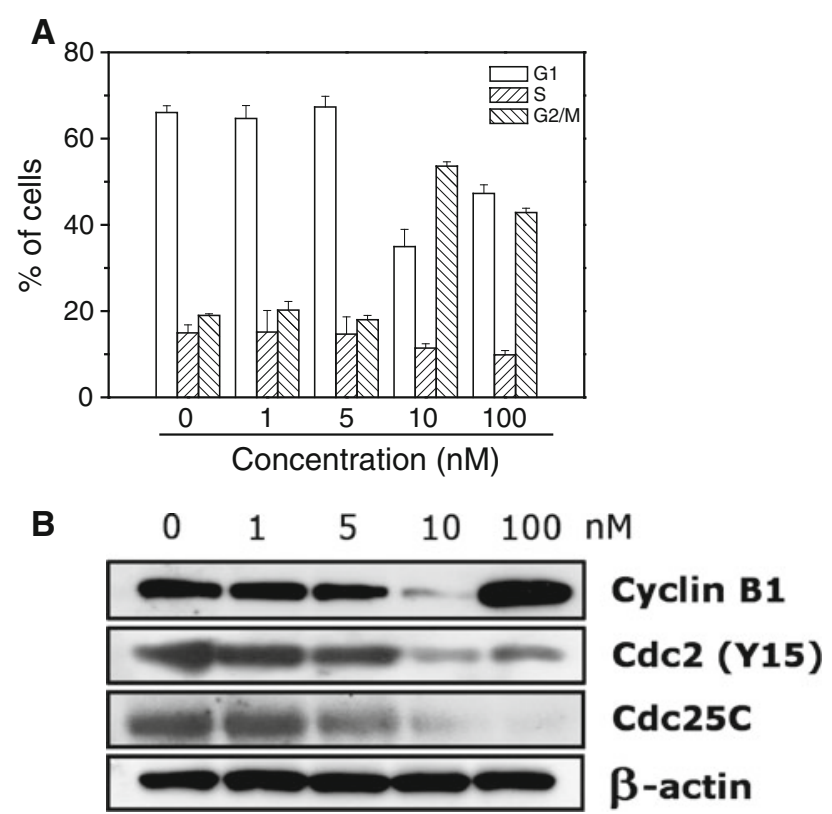

Fig. 6 a Effect of compound TR-644 on cell cycle distribution of HUVEC cells. Cells were treated with different concentrations, ranging from 1 to $100 \mathrm{nM}$ for $24 \mathrm{~h}$. Then the cells were fixed and stained with PI to analyze DNA content by flow cytometry. Data are presented as mean \pm SEM of three independent experiments. b Effect of TR-644 on G2/M regulatory proteins. HUVEC cells were treated for $24 \mathrm{~h}$ with the indicated concentrations. The cells were harvested and lysed for the detection of cyclin B, p-cdc2 $2^{\text {Tyr15 }}$ and cdc 25 c expression by western blot analysis. To confirm equal protein loading, each membrane was stripped and reprobed with anti- $\beta$-actin antibody

VE-cadherin is linked to the actin-myosin cytoskeleton via $\beta$-catenin. The cytoskeleton plays a central role in the regulation of endothelial permeability and cell migration by controlling cell shape $[4,30]$. Activation of the endothelial contractile machinery and generation of contractile forces by endothelial cells can cause adjacent cells to retract from each other.

The linkage of the cytoplasmic region of VE-cadherin with the actin cytoskeleton is mediated by a number of proteins, including $\alpha$ - and $\beta$-catenin, p120, and plakoglobin, and their interactions with VE-cadherin tend to strengthen adherens junctions [28]. Immunofluorescent analysis revealed a partial co-localization of VE-cadherin and $\beta$-catenin in untreated cells at the junctions between cells (Fig. 9, panel B).

On the other hand, the expression of VE-cadherin was strongly reduced in the presence of TR-644 both at 10 and $100 \mathrm{nM}$. More importantly, the cell-cell contacts appeared destroyed by the treatment and in control cells, VE-cadherin staining occurs on the surface suggesting that TR-644 is able to disrupt the cadherin/catenin complex and that the disruption of this complex may be responsible for the disruption in cell-cell adhesion.
TR-644 induces increase of cell adhesion without interfering with focal adhesion kinase (FAK)

Focal adhesion kinase (FAK) is a $125-\mathrm{kDa}$ non-receptor tyrosine kinase, which acts as a scaffold at sites of cell attachment to the extracellular matrix (ECM) and is activated following binding of integrins to ECM or upon growth factor stimulation including VEGF [31-33]. As a result, it regulates cell shape, cell adhesion and cell motility [33]. Since TR-644 inhibits cell migration, we examined if it is able to inhibit the formation of focal adhesions and the VEGF-induced phosphorylation of FAK. As shown in Fig. 9 (panel A), VEGF induced an increase of FAK phosphorylation at Tyr397 while the treatment with TR-644 slight increased its phosphorylation, both at 10 and $100 \mathrm{nM}$. CA4 also increased the expression of FAK $^{\text {Tyr397 }}$. To further investigate the effect of TR-644 on FAK we analyzed HUVEC cells by immunofluorescence. As showed in Fig. 9 (panel C), we observed that focal adhesions were distributed in a punctiform pattern along the cell periphery and TR-644 did not change the expression of focal adhesion both in the absence and in presence of VEGF. These results could appear in contrast with the inhibition of cell migration induced by the compound, indeed they are consistent with the increase in HUVEC cells adhesion induced by TR-644 (Fig. 9, panel D).

TR-644 treatment inhibits in vivo angiogenesis in CAM assay

TR-644 was assessed for its anti-angiogenic activity in vivo on the chick embryo chorioallantoic membrane (CAM). To this purpose, alginate beads containing FGF were applied topically on the CAM at day 11 of development in the absence or in the presence of TR-644 or CA4. As showed in Fig. 10 (panels A and B), FGF alone, triggered a potent angiogenic response that was significantly inhibited by TR644 (panel A), also at the lowest concentration used $(0.01 \mathrm{nmol} / \mathrm{egg})$. Interestingly, TR-644 did not induce any effect on the basal vascularization of the CAM and did not affect the development and survival of the chick embryos (data not shown). In contrast, CA4 (panel B) in the absence of FGF, induced a significant increase of the basal vasculature at all the concentration used. It has recently been shown, that the formation of new vessels in CAM could be driven by a pro-inflammatory signature, characterized by the upregulation of proinflammatory cytokine/chemokines and their receptors, endothelial cells adhesion molecules, and members of the eicosanoid pathway [34]. Thus, this effect could be due to an inflammatory response triggered by cellular damage induced by CA-4. Indeed hematoxylinheosin staining of the CAM showed a remarkable appearance of multiple site of inflammation along with the 
Fig. 7 Effect of TR-644 on microtubules in HUVEC. Cells were incubated for $24 \mathrm{~h}$ with the indicated concentration of TR644 or CA-4 as comparison and stained with anti- $\beta$-tubulin primary antibody and secondary Alexa-conjugated antibody and then observed by confocal microscopy (magnification $\times 20$ Bar $=10 \mu \mathrm{m})$. Cells were also counterstained with DAPI to visualize the nuclei. Insets represent magnification at $\times 60$, of a portion of the field
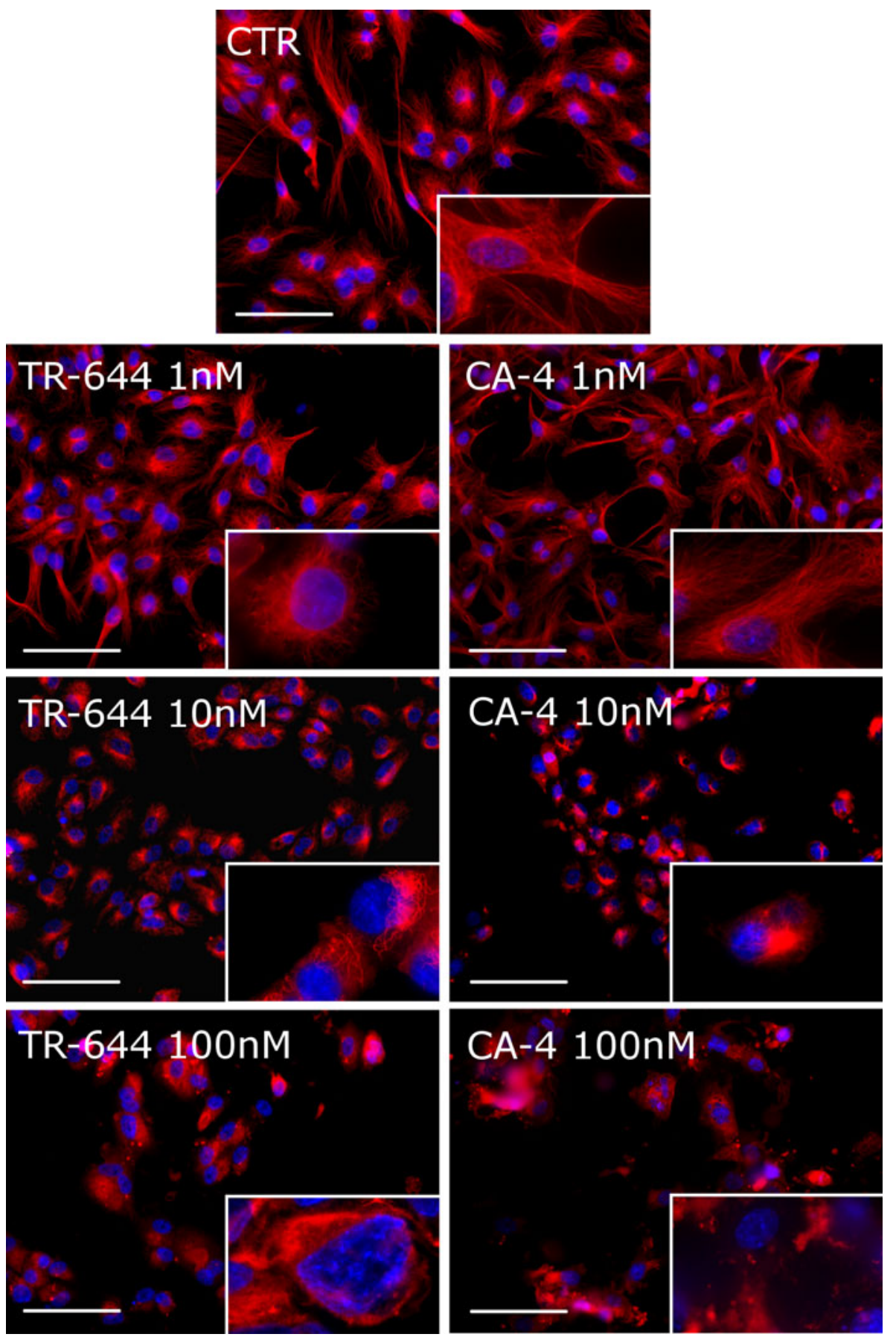

recruitment of lymphocytes and macrophages in CA4treated samples (Fig. 10, panel C).

TR-644 disrupts tumor vasculature in vivo tumor model

BL6-B16 mouse melanoma cell line were injected s.c. in syngeneic C57BL/6 mice. CD31 is expressed on vessels and is the most specific and sensitive endothelial marker currently available. A single i.p. administration of TR-644
(30 mg/Kg) significantly reduced tumor blood vasculature as determined by immunohistochemical staining with the antibody reactive to CD31 in brown color (Fig. 11, panel B). Also CA4-P significantly reduced the number of CD31 positive cells per field in well agreement with previous reports [29].

Moreover, we also tested whether TR-644 causes histological changes in tumor tissue by staining with hematoxilin and eosin (HE) and measuring proliferation using PCNA staining. The HE staining suggested that $24 \mathrm{~h}$ after a 
Fig. 8 Effect of TR-644 on actin microfilaments in HUVEC. Cells were incubated for $24 \mathrm{~h}$ with the indicated concentration of TR-644 or CA4 as comparison and stained with phalloidin-

tetramethylrhodamine B isothiocyanate conjugate. Cells were also counterstained with DAPI to visualize the nuclei (magnification $\times 60$ )
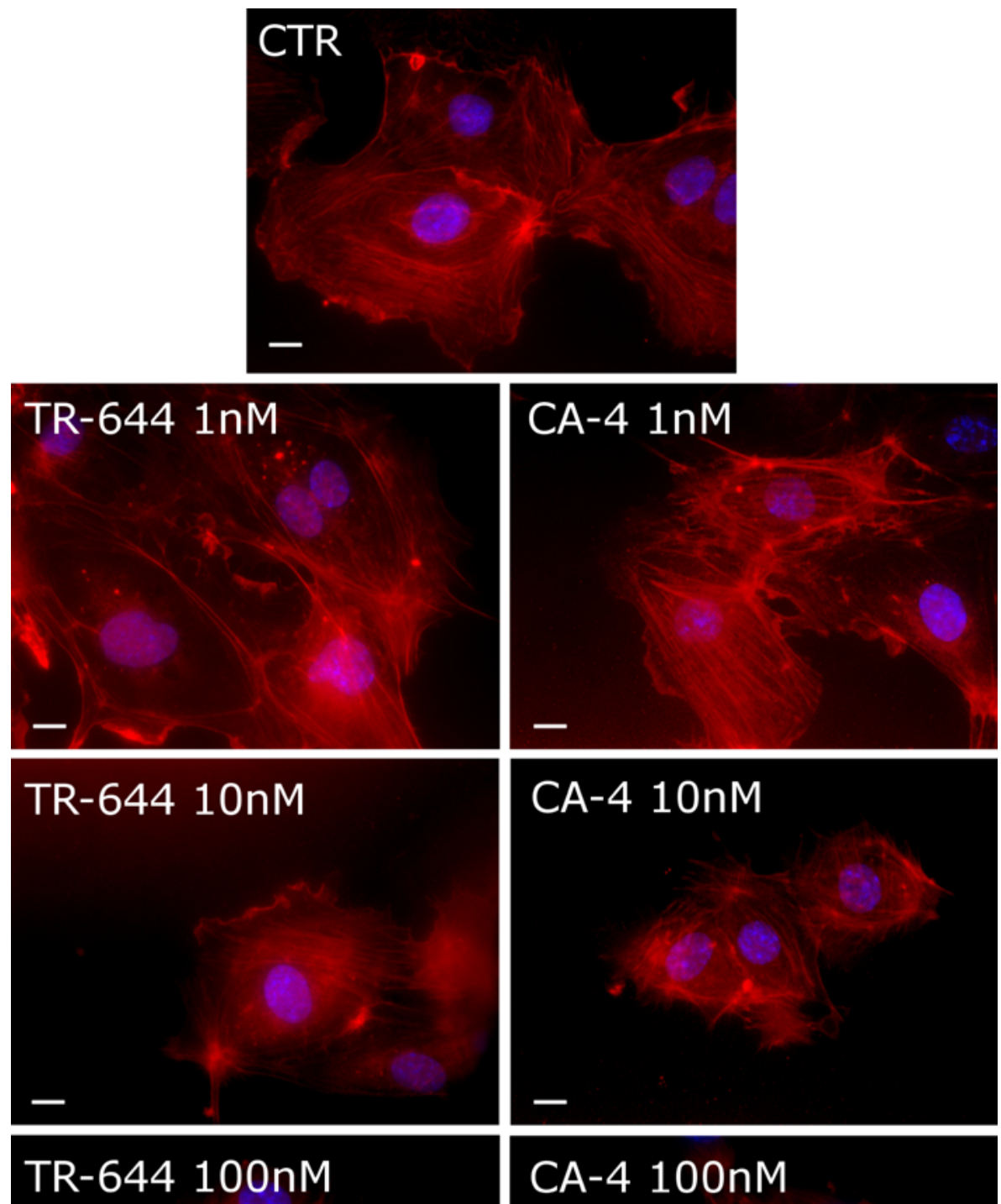

CA-4 100nM single i.p. injection of TR-644, there was a massive area of necrosis within tumor for both compounds. The number of PCNA positive cells, can be used as an index of cell proliferation. As showed in Fig. 11 (panel C), cell proliferation in the whole tumor significantly decreased after TR644, while CA4-P did not. These results are in well agreement with the higher antiproliferative activity of TR644 in many tumor cell lines relative to the lead compound CA-4 [15].

\section{Discussion}

We previously demonstrated that TR-644 displayed effective antiproliferative activity in numerous cell lines derived from human solid tumors and leukemias, including multidrug resistant cell lines [15]. We also showed that TR-644 induced depolymerization of tubulin and inhibited normal spindle formation in HeLa cells, resulting in mitotic arrest and cell death. The inhibition of tubulin polymerization 
A

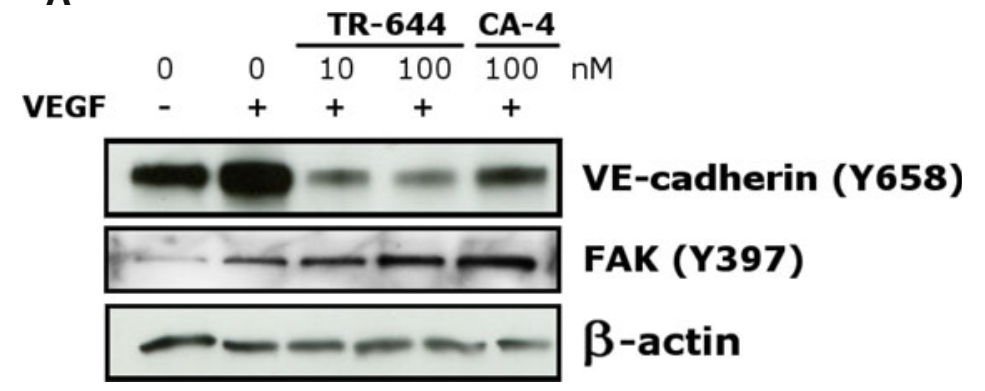

B

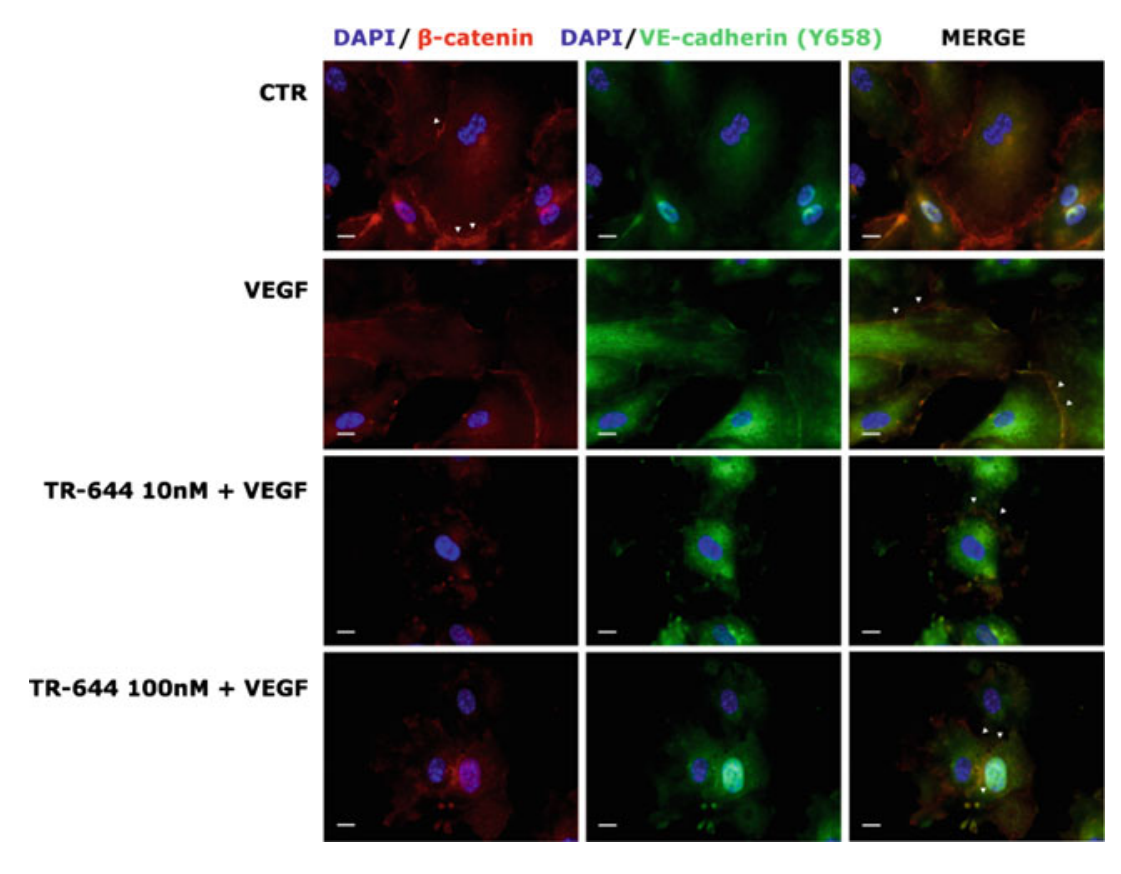

C

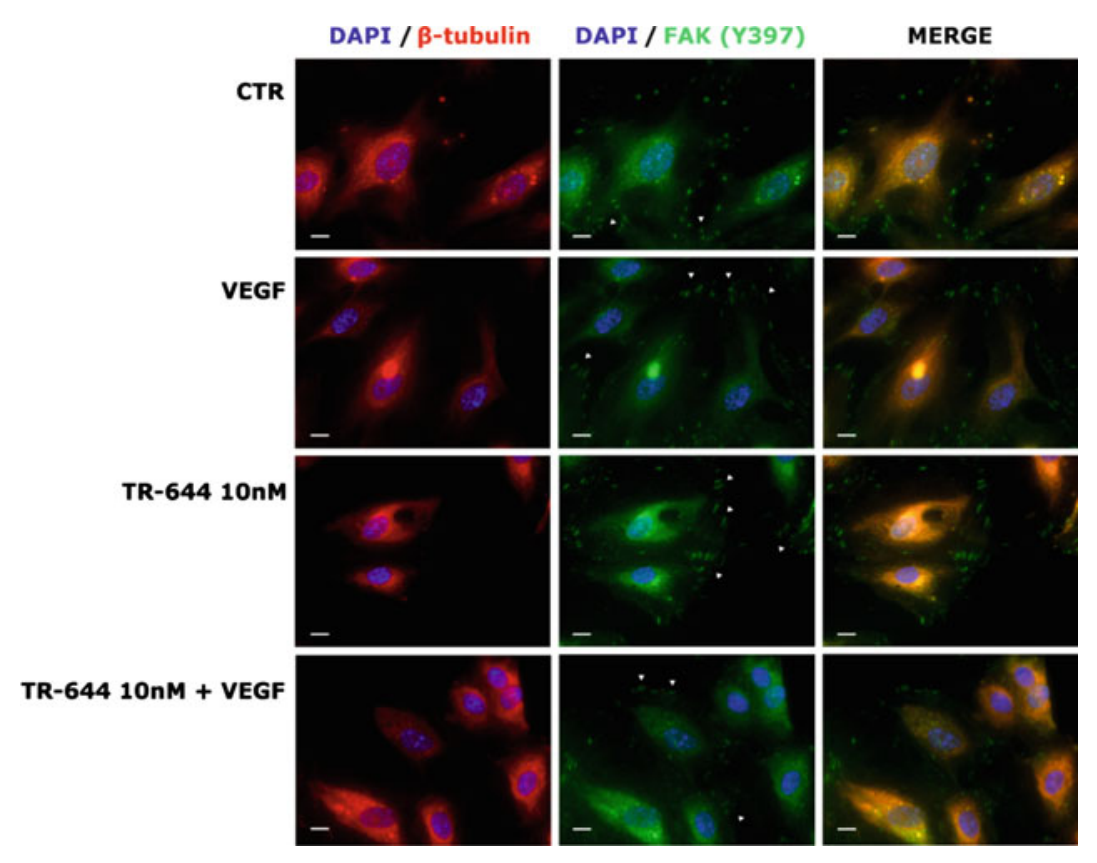


Fig. 9 Effect of TR-644 on VE-cadherin and FAK. a Western blot analysis of VE-Cadherin ${ }^{\mathrm{Y} 658}$ and $\mathrm{FAK}^{\mathrm{Y} 397}$ after $6 \mathrm{~h}$ of treatment with TR-644 and CA-4 at the indicated concentration in the presence of VEGF. b Immunofluorescence analysis of HUVEC cells treated with the indicated concentration of TR644 for $6 \mathrm{~h}$ and then stained with anti $\beta$-catenin antibody and anti VE-cadherin ${ }^{\mathrm{Y} 658}$ antibody. Cells were also counterstained with DAPI to visualize the nuclei (magnification $\times 40$ ). c Immunofluorescence analysis of HUVEC cells treated with the indicated concentration of TR-644 for $6 \mathrm{~h}$ and then stained with anti $\beta$-tubulin antibody and anti $\mathrm{FAK}^{\mathrm{Y} 397}$ antibody. Cells were also counterstained with DAPI to visualize the nuclei (magnification $\times 40$ ). Arrows indicate focal adhesions. d TR-644 enhances HUVEC cell adhesion. Data represent mean \pm SEM of three independent experiments performed in triplicate

was similar to that observed with the reference compound CA4. Examination of the effects of TR-644 on $\left[{ }^{3} \mathrm{H}\right]$ colchicine binding to tubulin revealed that colchicine binding was efficiently inhibited, indicating that TR644 binds tubulin in the colchicine site.
In this study, we demonstrated that TR-644 is a potent vascular disrupting agent that exhibit antivascular activity both in vitro and in vivo experiments. Motility and migration of vascular endothelial cells are important in the angiogenic process. We found that TR-644, at namolar concentration range, induces a significant inhibitory effect on endothelial cell migration. In addition, TR-644 inhibits both the organization of HUVEC into vessel-like tubes and disrupts established endothelial cell tubes in a concentration dependent manner. These effects are similar to that of the lead compound CA4.

Given the correlation between G2/M phase arrest and cytoskeletal dynamics, we investigated the effect of TR644 on the cell cycle. As other microtubule-binding agents TR-644 induces a G2/M phase arrest along with a remarkable reduction of the G1 phase while the $S$ phase is only slight affected. During a normal cell cycle, the
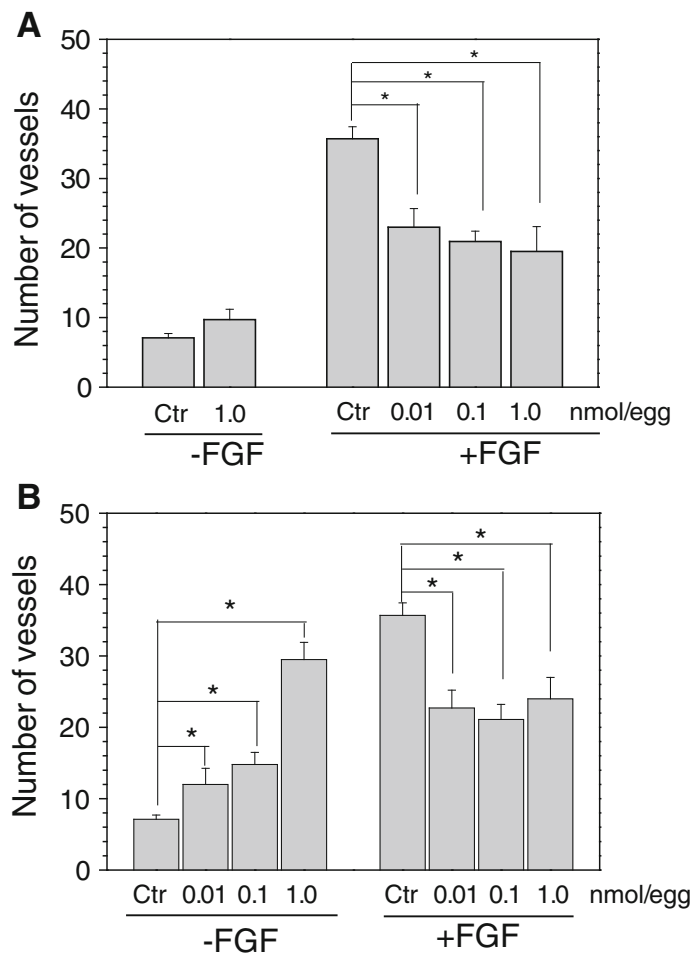
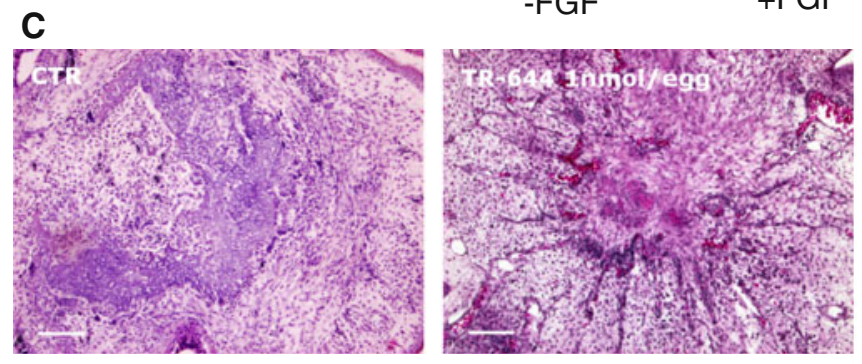

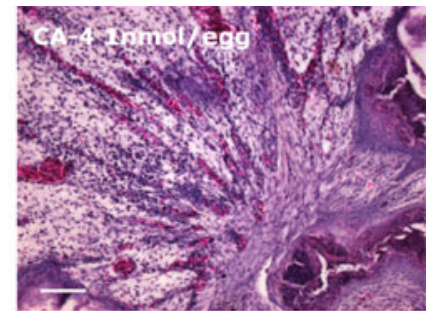

Fig. 10 In vivo effects of TR-644 (a) and CA4 (b) on chorioallantoic membrane (CAM) assay. Alginate sponges embedded with FGF $(150 \mathrm{ng})$, a stimulator of blood vessel formation, in the presence of the indicated doses of compounds were implanted on the top of the growing CAM on day 11 of development. On day 14, newly formed blood vessels converging toward the implants are counted at microscopic levels. Data represent mean \pm SEM of at least 10 eggs for groups. $* P<005$; $* * P<0.01$ versus control. c Histological pictures obtained from the CAM assay in the absence of FGF (hematoxylin-eosin staining $\times 60$ magnification) 
A
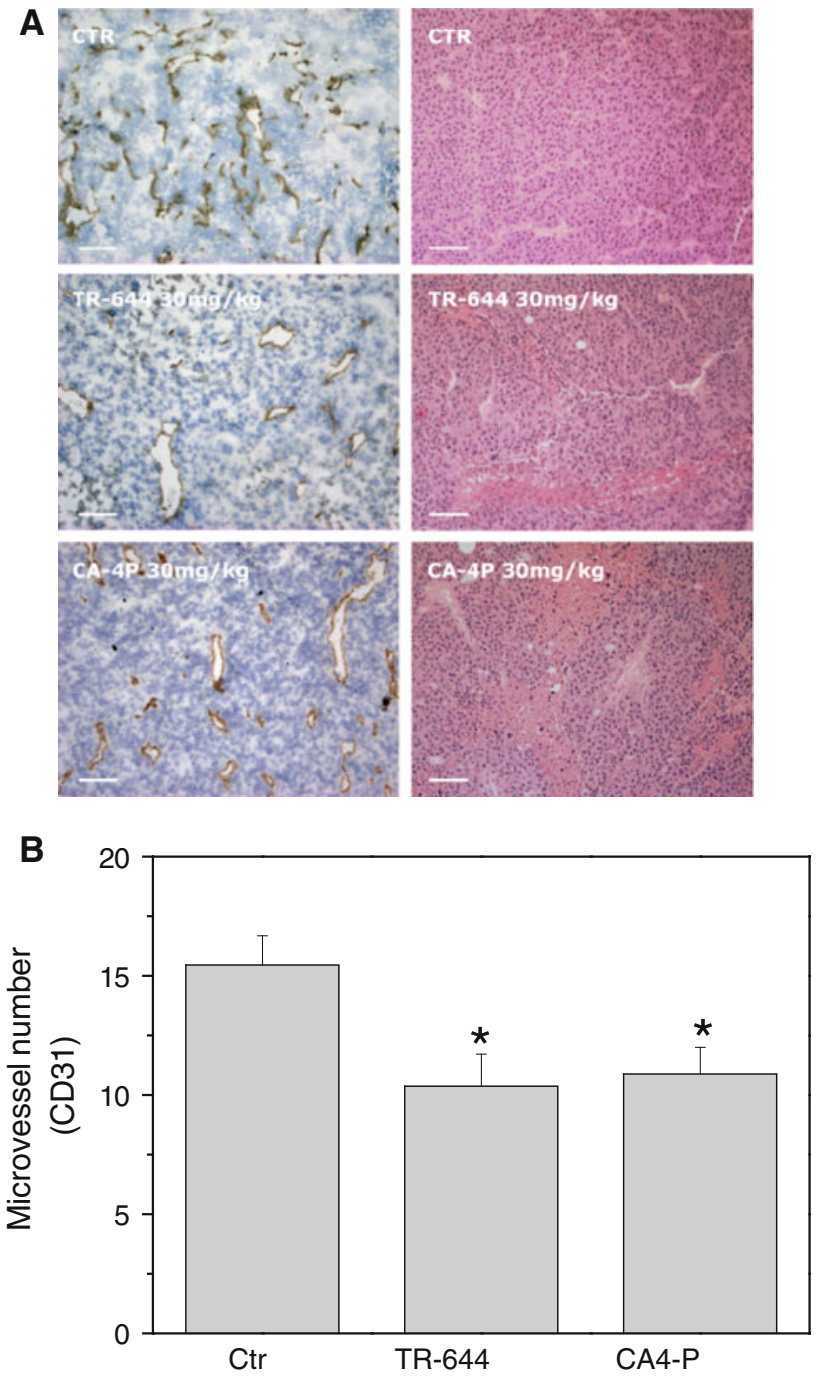

C

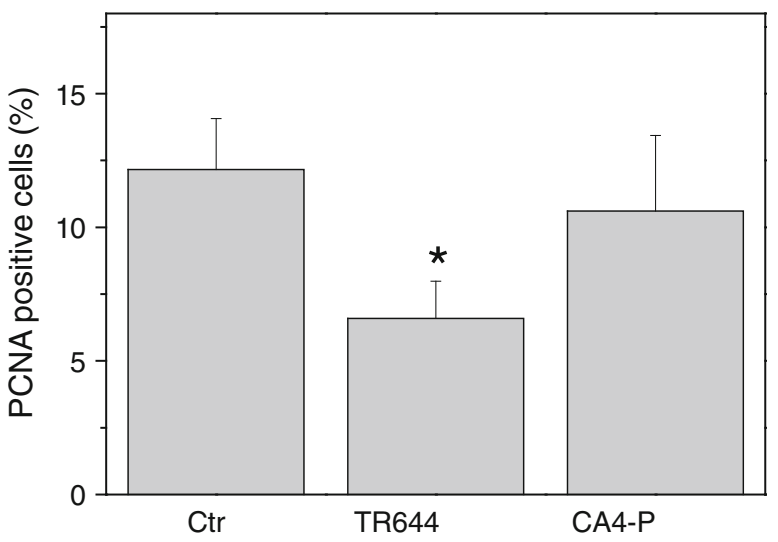

progression of cells in the $\mathrm{G} 2$ phase to $\mathrm{M}$ phase is triggered by the activation of the cyclin B1-dependent Cdc2 kinase $[35,36]$, which is regulated by a series of phosphorylationdephosphorylation events and protein-protein interactions [37]. At the G2/M phase transition, Cdc2 is dephosphorylated on $\mathrm{Tyr}^{15}$ and $\mathrm{Thr}^{14}$ and this event lead to activation
Fig. 11 Efficacy in vivo of TR-644 in a syngeneic mouse model. BL6-B16 murine melanoma cells were injected in the right flank of C57BL/6 mice as described in "Materials and methods". Tumor tissues were embedded in OCT-compound and frozen for immunohistochemistry. a CD31 immunohistochemistry and hematoxylineosin (HE) staining of tumor after i.p. treatment with $30 \mathrm{mg} / \mathrm{kg}$ of both TR-644 or CA4-P ( $\times 100$ magnification). b Quantitative analysis of tumor section stained with CD31. Data are represented as mean \pm SEM of five mouse per group $* P<0.05$ versus control. c Quantitative analysis of tumor section stained with PCNA. Data are represented as mean \pm SEM of five mouse per group $* P<0.05$ versus control

of the Cdc2 kinase and entry of cells into mitosis. Treatment with TR-644 decreases the phosphorylation of at $\mathrm{Cdc} 2$ at $\mathrm{Tyr}^{15}$ and the expression of the phosphatase $\mathrm{Cd} 25 \mathrm{c}$ both at 10 and $100 \mathrm{nM}$. Curiously enough we observed a dual effect of TR-644 on cyclin B1 expression: while at $10 \mathrm{nM}$ we observed a down regulation of cyclin B1 expression at higher concentration we found the opposite. This could be due to the fact that at low concentration a part of the cells are still able to exit from mitosis, while at higher concentration the cell arrest becomes irreversible and consequently the cyclin B1 expression increased.

TR-644 increases vascular permeability probably by disrupting endothelial cell-cell contact, and preventing organization of cellular connections that are critical for their survival and maintenance. These effects could be attributed to the inhibition of VE-cadherin phosphorylation. Indeed TR-644 strongly inhibits the phosphorylation of VE-cadherin induced by VEGF and reduces cell-cell contacts. Interestingly such analysis also clearly show a dissociation of the VE-cadherin/ $\beta$-catenin complex. Since VE-cadherin is linked and interacts with actin fibers via $\beta$ catenin, it is reasonable that the effect of TR-644 on cytoskeleton may contribute to the disconnection of homophilic VE-cadherin/ $\beta$-catenin-mediated cell-cell interactions. In this context it is worthwhile to note that also CA4 was demonstrated to increase endothelial cell permeability through disruption of the VE-cadherin/ $\beta$-catenin signaling [29].

It is interesting to note that all these effects occur at concentration that per se did not induce significant effects on endothelial cell proliferation while it appears that in HUVEC TR-644 is endowed with a lower cytotoxicity in comparison to the lead compound CA4.

FAK plays a central role during focal adhesion complex assembly and disassembly, that are critical for cell adhesion and migration. When FAK is activated, it is autophosphorylated at its autophosphorylation site $\mathrm{Tyr}^{397}$, binds to Src, which in turn phosphorylates other sites on FAK and the FAK-binding proteins, such as Cas and paxillin, which modulates cytoskeleton re-arrangement [31]. Moreover, inhibition of FAK phosphorylation greatly impairs cell spreading and adhesion [31]. Some anti mitotic 
drugs such as laulilamide [38] and taxotere [39] have been previously found to block the formation of focal adhesion and the autophosphorylation of FAK.

However, in TR-644-treated HUVEC, we found that FAK phosphorylation at Tyr397 is slight increased compared with the VEGF-treated cells. These high levels of FAK $^{\text {Tyr397 }}$ could prevent focal adhesion disassembly, leading to impaired cell migration. Recent evidences suggest that the level of phosphorylated FAK increases during focal adhesion formation [40]. The behavior of TR-644 is similar to JG-03-14, a new substituted pyrrole derivative which has been showed to affect endothelial cells function through inhibition of VE-cadherin but without interfering with FAK phosphorylation or focal adhesion formation [41]. It is worth noting that TR-644 increases actin stress fiber formation and in a recent study [42], the increased formation of intracellular stress fibers were correlated with enhanced cell adhesion in mammary cells, whereas migrating cells had fewer stress fibers. Indeed we also found that TR-644 significantly increases HUVEC adhesion suggesting that inhibition of cell migration may be linked to an activation of FAK signaling. To evaluate the ability of the TR-644 to interfere with the angiogenic process in vivo, we used the CAM assay as a model of neovessel formation, and observed that TR-644 significantly reduces the number of newly formed vessels in the CAM even at very low doses $(0.01 \mathrm{nmol} / \mathrm{egg})$. The effect was observed in the absence of any effect on embryonic development and survival and TR-644 had no toxic effects on preexisting vessels (data not shown). This is in accordance with our in vitro findings that showed a lower cytotoxicity of TR-644 respect to CA4. Surprisingly CA4 at all concentration tested induces per se a significant increase of the vasculature mimicking the effects of FGF. Recent papers [34, 43], indicate that inflammatory cytokines, as early mediators of inflammation, are a potent angiogenic factors, suggesting that angiogenesis and inflammation are closely integrated processes. In this context the pro-angiogenic effect of CA4 in the absence of FGF could be due to a cell damage effect of CA4 that in some way produces the recruitment of inflammatory cells that consequently induces neovascularization. Accordingly, histological examination of CAM showed a remarkable monocyte/macrophage infiltrate in the area in which the alginate pellet containing CA4 was located. It is worthwhile to note that anti-inflammatory agents exert antiangiogenic effects. Further in vivo experiments carried out with mouse melanoma tumor model demonstrated that a single injection of TR-644 efficiently and selectively destroy vasculature of tumor tissue and induce a significant reduction of tumor cell proliferation as demonstrated by reduction in PCNA positive cells. In summary our study provides for the first time evidence that administration of
TR-644 causes inhibition of angiogenesis both in vitro and in vivo at a concentration that is not cytotoxic for endothelial cells indicating that TR-644 may be a promising candidate as inhibitor of angiogenesis.

Conflict of interest The authors declare that they have no conflict of interest.

\section{References}

1. Jordan MA, Wilson L (2004) Microtubules as a target for anticancer drugs. Nat Rev Cancer 4:253-265

2. Dumontet C, Jordan MA (2010) Microtubule-binding agents: a dynamic field of cancer therapeutics. Nat Rev Drug Discov 9:790-803

3. Tozer GM, Kanthou C, Baguley BC (2005) Disrupting tumor blood vessel. Nat Rev Cancer 5:423-435

4. Schwartz EL (2009) Antivascular actions of microtubule-binding drugs. Clin Cancer Res 15:2594-2601

5. Grosios K, Holwell SE, McGown AT, Pettit GR, Bibby MC (1999) In vivo and in vitro evaluation of combretastatin A-4 and its sodium phosphate prodrug. Br J Cancer 81:1318-1327

6. Gaukroger K, Hadfield JA, Lawrence NJ, Nlan S, McGown AT (2003) Structural requirements for the interaction of combretastatins with tubulin: how important is the trimethoxy unit? Org Biomol Chem 1:3033-3037

7. Tron GC, Pirali T, Sorba G, Pagliai F, Busacca S, Genazzani AA (2006) Medicinal chemistry of combretastatin A4: present and future directions. J Med Chem 49:3033-3044

8. Wang L, Woods KW, Li Q, Barr KJ, McCroskey RW, Hannick SM, Gherke L, Credo RB, Hui YH, Marsh K, Warner R, Lee JY, Zielinski-Mozng N, Frost D, Rosenberg SH, Sham HL (2002) Potent, orally active heterocycle-based combretastatin A-4 analogues: synthesis, structure-activity relationship, pharmacokinetics, and in vivo antitumor activity evaluation. J Med Chem 45:1697-1711

9. Schobert R, Biersack B, Dietrich A, Effenberger K, Knauer S, Mueller T (2010) 4-(3-Halo/amino-4,5-dimethoxyphenyl)-5-aryloxazoles and $\mathrm{N}$-methylimidazoles that are cytotoxic against combretastatin A resistant tumor cells and vascular disrupting in a cis platin resistant germ cell tumor model. J Med Chem 53:6595-6602

10. Ohsumi K, Hatanaka T, Fujita K, Nakagawa R, Fukuda Y, Nihai Y, Suga Y, Morinaga Y, Akiyama Y, Tsuji T (1988) Synthesis and antitumor activity of cis-restricted combretastatins 5-membered heterocyclic analogues. Bioorg Med Chem Lett 8:3153-3158

11. Tron GC, Pagliai F, Del Grosso E, Genazzani AA, Sorba G (2005) Synthesis and cytotoxic evaluation of combretafurazans. J Med Chem 48:3260-3268

12. Liu T, Dong X, Xue N, Wu R, He Q, Yang B, Hu Y (2009) Synthesis and biological evaluation of 3,4-biaryl-5-aminoisoxazole derivatives. Bioorg Med Chem 17:6279-6285

13. Wu M, Li W, Yang C, Chen D, Ding J, Chen Y, Lin L, Xie Y (2007) Synthesis and activity of combretastatin A-4 analogues: 1,2,3-thiadiazoles as potent antitumor agents. Bioorg Med Chem Lett 17:869-873

14. Romagnoli R, Baraldi PG, Cruz-Lopez O, Lopez-Cara C, Carrion MD, Brancale A, Hamel E, Chen L, Bortolozzi R, Basso G, Viola G (2010) Synthesis and antitumor activity of 1,5-disubstituted 1,2,4-triazoles as cis-restricted combretastatin analogs. J Med Chem 53:4248-4258

15. Romagnoli R, Baraldi PG, Brancale A, Ricci A, Hamel E, Bortolozzi R, Basso G, Viola G (2011) Convergent synthesis and 
biological evaluation of 2-amino-4-( $3^{\prime}, 4^{\prime}, 5^{\prime}$-trimethoxyphenyl)-5aryl thiazoles as microtubule targeting agents. J Med Chem 54:5144-5153

16. Pettit GR, Singh SB, Hamel E, Lin CM, Alberts DS, GarciaKendall D (1989) Isolation and structure of the strong cell growth and tubulin inhibitor combretastatin A-4. Experentia 45:209-211

17. Pettit GR, Temple C Jr, Narayanan VL, Varma R, Boyd MR, Rener GA, Bansal N (1995) Antineoplastic agents 322. Synthesis of combretastatin A-4 prodrugs. Anticancer Drug Des 10: 299-309

18. Pettit GR, Singh SB, Boyd MR, Hamel E, Pettit RK, Schmidt JM, Hogan F (1985) Antineoplastic agents. 291. Isolation and synthesis of combretastatins A-4, A-5, and A-6(1a). J Med Chem 38:1666-1672

19. Mitola S, Strasly M, Prato M, Ghia P, Bussolino F (2003) IL-12 regulates an endothelial cell-lymphocyte network: effect on metalloproteinase-9 production. J Immunol 171:3725-3733

20. Basili S, Basso G, Faccio A, Granzhan A, Ihmels H, Moro S, Viola G (2008) Diazoniapolycyclic ions inhibit activity of topoisomerase I and growth of certain tumor cell lines. ChemMedChem 3:1671-1676

21. Liang CC, Park AY, Guan JL (2007) In vitro scratch assay: a convenient and inexpensive method for analysis of cell migration in vitro. Nat Protoc 2:329-333

22. Guidolin D, Vacca A, Nussdorfer GG, Ribatti D (2004) A new image analysis method based on topological and fractal parameters to evaluate the angiostatic activity of docetaxel by using the Matrigel assay in vitro. Microvasc Res 67:117-124

23. Viola G, Fortunato E, Cecconet L, Del Giudice L, Dall'Acqua F, Basso G (2008) Central role of mitochondria and p53 in PUVAinduced apoptosis in human keratinocytes cell line NCTC-2544. Toxicol Appl Pharmacol 227:84-96

24. Chiodelli P, Mitola S, Ravelli C, Oreste P, Rusnati M, Presta M (2011) Heparan sulfate proteoglycans mediate the angiogenic activity of the vascular endothelial growth factor receptor-2 agonist gremlin. Arterioscler Thromb Vasc Biol 31:e116-e127

25. Dejana E, Giampietro C (2012) Vascular endothelial-cadherin and vascular stability. Curr Opin Hematol 19:218-223

26. Vittet D, Buchou T, Schweitzer A, Dejana E, Huber P (1997) Targeted null-mutation in the vascular endothelial-cadherin gene impairs the organization of vascular-like structures in embryoid bodies. Proc Natl Acad Sci USA 94:6273-6278

27. Feraud O, Cao Y, Vittet D (2001) Embryonic stem cell-derived embryoid bodies development in collagen gels recapitulates sprouting angiogenesis. Lab Invest 81:1669-1681

28. Dejana E, Orsenigo F, Lampugnani MG (2008) The role of adherens junctions and VE-cadherin in the control of vascular permeability. J Cell Sci 121:2115-2122

29. Vincent L, Kermani P, Young LM, Cheng J, Zhang F, Shido K, Lam G, Bompais-Vincent H, Zhu Z, Hicklin DJ, Bohlen P, Chaplin DJ, May C, Rafii S (2005) Combretastatin A4 phosphate induces rapid regression of tumor neovessels and growth through interference with vascular endothelial-cadherin signaling. J Clin Invest 115:2992-3006
30. Bogatcheva NV, Verin AD (2008) The role of cytoskeleton in the regulation of vascular endothelial barrier function. Microvasc Res 76:202-207

31. Mitra SK, Hanson DA, Schlaepfer DD (2005) Focal adhesion kinase: in command and control of cell motility. Nat Rev Mol Cell Biol 6:56-68

32. Herzog B, Pellet-Many C, Britton G, Hartzoulakis B, Zachary IC (2011) VEGF binding to NRP1 is essential for VEGF stimulation of endothelial cell migration, complex formation between NRP1 and VEGFR2, and signaling via FAK Tyr407 phosphorylation. Mol Biol Cell 22:2766-2776

33. Chen XL, Nam JO, Jean C, Lawson C, Walsh CT, Goka E, Lim ST, Tomar A, Tancioni I, Uryu S, Guan JL, Acevedo LM, Weis SM, Cheresh DA, Schlaepfer DD (2012) VEGF-induced vascular permeability is mediated by FAK. Dev Cell 22:146-157

34. Andrés G, Leali D, Mitola S, Coltrini D, Camozzi M, Corsini M, Belleri M, Hirsch E, Schwendener RA, Christofori G, Alcamí A, Presta M (2009) A pro-inflammatory signature mediates FGF2induced angiogenesis. J Cell Mol Med 13:2083-2108

35. Atherton-Fessler S, Liu F, Gabrielli B, Lee MS, Peng CY, Piwnica-Worms H (1994) Cell cycle regulation of the p34cdc2 inhibitory kinases. Mol Biol Cell 5:989-1001

36. Choi HJ, Fukui M, Zhu BT (2012) Role of cyclin B1/Cdc2 upregulation in the development of mitotic prometaphase arrest in human breast cancer cells treated with nocodazole. PLoS One 6:e24312

37. Mollinedo F, Gajate C (2003) Microtubules, microtubule-interfering agents and apoptosis. Apoptosis 8:413-450

38. Lu H, Murtagh J, Schwartz EL (2006) The microtubule binding drug laulimalide inhibits vascular endothelial growth factorinduced human endothelial cell migration and is synergistic when combined with docetaxel (taxotere). Mol Pharmacol 69: 1207-1215

39. Murtagh J, Lu H, Schwartz EL (2006) Taxotere-induced inhibition of human endothelial cell migration is a result of heat shock protein 90 degradation. Cancer Res 66:8192-8199

40. Qin L, Zhang M (2010) Maspin regulates endothelial cell adhesion and migration through an integrin signaling pathway. J Biol Chem 285:32360-32369

41. Dalyot-Herman N, Delgado-Lopez F, Gewirtz DA, Gupton JT, Schwartz EL (2009) Interference with endothelial cell function by JG-03-14, an agent that binds to the colchicine site on microtubules. Biochem Pharmacol 78:1167-1177

42. Katz M, Amit I, Citri A, Shay T, Carvalho S, Lavi S, Milanezi F, Lyass L, Amariglio N, Jacob-Hirsch J, Ben-Chetrit N, Tarcic G, Lindzen M, Avraham R, Liao YC, Trusk P, Lyass A, Rechavi G, Spector NL, Lo SH, Schmitt F, Bacus SS, Yarden Y (2007) A reciprocal tensin-3-cten switch mediates EGF-driven mammary cell migration. Nat Cell Biol 9:961-969

43. Presta M, Andrés G, Leali D, Dell'Era P, Ronca R (2009) Inflammatory cells and chemokines sustain FGF2-induced angiogenesis. Eur Cytokine Netw 20:39-50 